\title{
Predominancia de la educación emocional occidental en contexto indígena: necesidad de una educación culturalmente pertinente
}

\author{
Enrique Riquelme Mella \\ Universidad Católica de Temuco - Chile \\ Daniel Quilaqueo Rapimán \\ Universidad Católica de Temuco - Chile \\ Segundo Quintriqueo Millán \\ Universidad Católica de Temuco - Chile \\ Elisa Loncón Antileo \\ Universidad de Santiago de Chile - Chile
}

\section{Resumen}

Este artículo es de carácter teórico, en él reflexionamos sobre el desafío de revisar los marcos sobre la educación emocional que necesita reconocer e identificar las variaciones de los problemas sociales y culturales asociadas a la educación familiar mapuche como eje de formación emocional propio. Partimos de la reconsideración de la dimensión emocional en la escuela, acompañada de investigaciones que apuntan al mejoramiento de ciertas habilidades emocionales tanto en los estudiantes como en los profesores. Este reconocimiento se asocia con un ideal de competencias emocionales o ideal emocional en el aula. Sin embargo, en este ideal de educación emocional, se ha dejado de considerar el saber emocional de los estudiantes que pertenecen a culturas de grupos minoritarios, donde el ideal emocional construido en el marco de la educación familiar puede distar del predominante en las escuelas. Esta situación de la escuela y la educación en contextos indígenas, puede generar choques culturales que, en contextos de diversidad social y cultural, pueden ser ignorados o mal interpretados, generando procesos de discriminación e inequidad. Esta problemática puede ser abordada desde una epistemología emocional propia; permitiendo el reconocimiento de la educación emocional y la identidad cultural mapuche mediante un enfoque educativo intercultural.

Palabras clave: Escuela; educación afectiva; educación familiar.

\section{Dominance of Western emotional education on indigenous context: the need for a culturally pertinent emotional education}

\begin{abstract}
In this theoretical article we reflect on the challenge of checking the frameworks related to the emotional education that need to recognize and identify the variations of the social and cultural problems associated with the mapuche family education as core of the own emotional formation. We start with a reconsideration of the emotional dimension of the school, accompanied by investigations that aim to the improvement of certain emotional skills in students as well as in professors. This recognition is associated with an ideal of emotional competencies or an emotional ideal in the classroom. Previously, however, in this ideal of emotional education, the emotional knowledge of the student who belongs to the culture of minority groups has not longer been considered, especially when the emotional ideal built on the framework of the family education may be far from the predominant one in the schools. When social and cultural diversity is ignored or misinterpreted in school and in education in indigenous contexts, cultural clashes emerge creating processes of discrimination and inequity. This problem can be addressed with a proper emotional epistemology, allowing for recognition of the emotional education and the mapuche cultural identity by using an intercultural educational approach.
\end{abstract}

Keywords: School; affective education; family education.

\section{Predomínio da educação emocional ocidental em contexto indígena: necessidade de uma educação culturalmente pertinente}

\section{Resumo}

Este artigo teórico reflete o desafio de rever contextos da educação emocional, precisamente para reconhecer e identificar mudanças nos problemas sociais e culturais associados à educação da família Mapuche como eixo da formação emocional. Começamos reconsiderando a dimensão emocional na escola, junto com uma investigação destinada a melhorar certas habilidades emocionais em alunos e professores. Este reconhecimento está associado a um ideal de competências emocionais e ideal emocional na sala de aula. No entanto, neste ideal de educação emocional se deixou de considerar o conhecimento emocional dos alunos que pertencem a culturas de grupos minoritários, em que o emocional construído idealmente no âmbito da educação familiar pode estar longe de ser dominante nas escolas. Esta situação da escola e da educação em contextos indígenas pode levar a choques culturais que, em contextos de diversidade social e cultural, podem ser ignorados ou mal interpretados, gerando processos de discriminação e desigualdade. Este problema pode ser abordado a partir de uma epistemologia emocional, permitindo o reconhecimento da educação emocional e identidade cultural Mapuche através de uma abordagem educativa intercultural.

Palavras-chave: Escola; educação afetiva; educação familiar. 


\section{Introducción}

Durante los últimos años hemos venido siendo testigos de una lenta, pero constante reconsideración de la dimensión emocional en la escuela; lo que ha venido acompañado de una serie de investigaciones y programas de intervención que apuntan a un mejoramiento de ciertas habilidades o competencias emocionales, tanto en los estudiantes como en los profesores (Saarni, 2008; Denham, Bassett, \& Zinsser, 2012; Riquelme \& Montero, 2013). Básicamente, la competencia emocional en la escuela es entendida como la demostración de eficacia emocional en las interacciones sociales (Bisquerra \& Pérez, 2007). Entre las competencias emocionales encontramos el reconocimiento de emociones en sí mismo y en los otros (Saarni, 1999), lo cual se desarrolla mediante la regulación emocional (Denham, Bassett, \& Zinsser, 2012). La regulación implica los siguientes procesos: (a) manejar las emociones de manera productiva, siendo consciente de los sentimientos, monitoreándolos y modificándolos cuando sea necesario, de modo que ayuden a afrontar diversas situaciones, y (b) expresar las emociones adecuadamente. Estas son solo algunas de las competencias emocionales básicas que son recomendadas en el desarrollo del niño en el nivel de enseñanza preescolar. Puesto que, la cantidad y naturaleza de las competencias emocionales varía según el enfoque teórico, el contexto de interacción social en el que se despliegan y, naturalmente, dependiendo de la edad.

El desarrollo de las competencias emocionales se vincula a los escenarios o contextos familiares y culturales, donde se delinean las pautas esperables para interpretar la emoción, como un proceso regular de socialización, para actuar emocionalmente o 'saber sentir' (Cole \& Tan, 2006; Friedlmeier, Corapci, \& Cole, 2011). Este es un elemento básico que parece omitirse en la educación emocional escolar. Desde esta perspectiva, los niños en un escenario educativo particular como el escolar, pueden estar respondiendo a formas socialmente aceptadas y culturalmente deseables que se dejan de considerar al intentar potenciar una misma competencia a todos los estudiantes (Riquelme \& Munita, 2013, 2016). Este hecho podría ser una limitante en contextos educativos de diversidad social y cultural, donde existe la presencia de estudiantes que poseen culturas diferentes, formas de sentir y competencias emocionales que se pueden desarrollar o negar desde la cultura dominante que enmarca la escuela. Esto es particularmente relevante cuando la escuela asume por válido un tipo de comportamiento emocional y lo somete a contraste en todos los niños, sin cuestionar si el modelo con el que contrasta requiere ser modificado, o si es sensible a las variaciones culturales (Riquelme \& Munita, 2016).

En un marco de interacción social, en contexto de diversidad social y cultural como el escolar, el comportamiento emocional de niños que pertenecen a pueblos indígenas como el mapuche, puede ser erróneamente interpretado como desajustado o como emocionalmente incompetente (Gallimore \& Hu-Peiau, 2002). Además, puede conducir a discriminación en el aula - tanto de profesores como estudiantes, sean éstos de ascendencia mapuche o no mapuche - así como a procesos de inequidad por parte de quienes forman parte de la cultura dominante (Chentsova-Dutton \& Wong, 2002; Ibáñez-Salgado, 2015). De esta forma, no solamente podemos observar los procesos históricos de discriminación escolar al excluir saberes educativos y culturales vernáculos (Foley, 2004). En la dimensión del saber emocional la exclusión vivenciada puede ser aún más sutil al discriminar al niño indígena, apartándolo 'por su propio bien' al no ajustarse a una forma de sentir deseable en el marco de la cultura escolar dominante (Riquelme \& Munita, 2011).

Efectivamente, el ideal emocional que predomina históricamente en la educación escolar instaurada en contextos de colonización indígena, especialmente en América Latina, está anclado en el pasado colonial. Puesto que, se apoya en el marco social y cultural eurocéntrico occidental, de carácter civilizatorio, jerarquizante, monocultural, hegemónico y homogeneizante, anclada en el pasado colonial (Quintriqueo, 2010). Es así como en el contexto educativo chileno los estudiantes de origen mapuche se han visto enfrentados a la discriminación y dominación sociocultural, como resultado del colonialismo instaurado en la escuela (Quintriqueo y cols., 2014). Esto ha generado, entre los mapuches, la pérdida del uso público del lenguaje propio, los referentes culturales y los aspectos emocionales. Sin embargo, estas dificultades han impulsado a los padres de familia la búsqueda constante y estable de un mejor desarrollo social, mediante su incorporación a la educación escolar monocultural occidental (Quilaqueo \& Quintriqueo, 2010). Esto ha implicado construir en el mapuche una racionalidad de 'producción y progreso' que habitualmente es contradictoria, sobre lo que es deseable en la familia y comunidad, en situación de sociedad minoritaria, para mantener e integrar su herencia cultural en este proceso (De Leersnyder, Mesquita, \& Kim, 2011). En este sentido, las dificultades que ha traído la escolarización son ampliamente reconocidas (Quilaqueo \& Merino, 2003) y todas ellas implican la construcción de un componente emocional central y representaciones sobre el saber sentir. Sin embargo, las variaciones de la dimensión emocional en el ámbito educativo se han reemplazado por un criterio común de desarrollo evolutivo emocional que sigue manteniendo las inequidades, ignorando los saberes propios y en consecuencia, propendiendo a una educación que reproduce la discriminación hacia los pueblos indígenas (Quilaqueo, Merino, \& Saiz, 2007; Tremblay, Gokiert, Georgis, Edwards, \& Skrypnek, 2013).

Una educación que busque el desarrollo de las personas debería reconocer y hacer visible la diversidad de los niños en el aula (DeAnquín \& Bazán, 2015; Ibanez, Diaz, Druker, \& Rodriguez, 2012), mediante la incorporación de conocimientos y saberes culturales propios del contexto sociocultural de los estudiantes, entre los que la emoción tiene un rol central (Boiger \& Mesquita, 2012). Esto requiere de una escuela que no sólo reconozca las emociones en sus dimensiones comunes, universales y evolutivas (Lewis, 1989, 2008), sino que además, respete las diferencias culturales 
en la forma de entender lo adecuado en el comportamiento emocional, según el contexto de interacción, y ofrezca una evaluación sensible a las diferencias sociales y culturales (Dunsmore \& Halberstadt, 2009; Halberstadt \& Lozada, 2011).

Considerando que las emociones son organizadas y gestionadas socialmente en los discursos y prácticas sociales de la familia y comunidad (Zembylas, 2011), es que se hace necesario reconocer - para una educación pertinente y respetuosa - los ideales emocionales que se encuentran presentes en los discursos socio-educativos de las familias mapuches, así como en actividades culturales donde se hacen evidentes las prácticas de socialización de la emoción. Así, la necesidad de reconocimiento requiere de un estudio comprensivo respecto de los conocimientos sobre la emoción y su socialización en la educación familiar mapuche. Puesto que, dichos conocimientos integran una representación sobre la emoción y lo emocional en los niños, la que es transmitida mediante la educación familiar mapuche.

El objetivo de este ensayo es reflexionar sobre la necesidad de construir un marco de educación emocional para una educación pertinente que reconozca las variaciones culturales asociadas a la forma en que se potencian determinadas competencias emocionales. Asimismo, reflexionamos sobre la construcción del conocimiento social en relación a la emoción que subyace a su expresión comportamental en distintos contextos de interacción social (Tremblay \& cols., 2013). Ponemos especial énfasis en la educación familiar mapuche como eje de los procesos de formación emocional propios. Finalizamos señalando los potenciales caminos a recorrer para avanzar hacia una educación emocional escolar con pertinencia social y cultural.

\section{Socialización del saber sentir y su correlato en la competencia emocional}

La competencia emocional incorpora el saber sentir en contextos sociales particulares. Como se ha señalado, un sujeto es competente emocionalmente en situaciones específicas que entregan lineamientos sobre lo deseable y adecuado culturalmente. Estos lineamientos constituyen guiones de acción dinámicos que operan inicialmente en los planos conductuales, para luego ser internalizados y organizados en modelos representacionales (Zubieta, Fernández, Vergara, Martínez, \& Candia, 2012). Estos son procesos recursivos de acción-internalización y representación de la emoción, que se articulan en actividades cotidianas de socialización y educación infantil. Durante estas interacciones se entregan - explícita o implícitamente - normas que señalan directrices emocionales expresadas en el lenguaje, sobre lo esperable o deseable en un contexto social, que luego son reforzadas culturalmente. Por ejemplo, Ronald de Sousa (1987) los ha denominado escenarios paradigmáticos:

Somos familiarizados con el vocabulario de la emoción por la asociación con escenarios paradigmáticos. Éstos son trazados en primer lugar de nuestra vida cotidiana como los niños pequeños y viene a ser reforzada por la historia, el arte y la cultura a la que estamos expuestos. Más tarde, en las culturas alfabetizadas, se complementan y refinan por la literatura. Los escenarios paradigmáticos implican dos aspectos: en primer lugar, una situación tipo que provee objetos característicos del tipo de emoción específica (donde los objetos pueden ser de varios tipos identificados en el capítulo 5), y en segundo lugar, un conjunto de respuestas características o "normales" a la situación, donde la normalidad es en primer lugar una cuestión biológica y luego muy rápidamente se convierte en una cultural. ${ }^{1}$ (p. 182).

Siguiendo esta hipótesis, un escenario paradigmático es entendido como una situación prototípica que refleja lo esperado culturalmente en distintas dimensiones, en particular el nivel emocional. Este escenario entrega guías orientadoras. Por ejemplo, la 'correcta' interpretación de lo que nos sucede desde nuestra sociedad y cultura, o el lenguaje que utilizamos para expresar nuestras emociones y sentimientos (Riquelme \& Munita, 2016; Riquelme, Munita, Jara, \& Montero, 2013). Russell (1991) se ha referido a ellos como 'escenarios prototípicos de estados afectivos', los que implican una representación internalizada de las emociones construidas en un proceso de negociación con figuras significativas. Es decir, la interacción social cotidiana promueve la aparición de constructos cognitivos y afectivos compartidos que proveen a los individuos de un marco de sentido común, a partir del cual es posible entender sus experiencias en el mundo.

En estos escenarios prototípicos se organizan guiones emocionales (Widen \& Rusell, 2010; 2011) que cognitivamente ordenan las secuencias de conductas que integran emoción, de modo que no solo vemos una emoción aislada, sino un conjunto de acciones con un sentido. Desde un plano más social, los guiones surgen de la necesidad humana de ordenar y explicar el mundo. Así, se construyen marcos de referencia que no sólo nos permiten entender el mundo, sino que además, nos permiten conducirnos en él. Desde esta perspectiva, podemos entender las emociones como una dimensión de construcción social sobre las cuales podemos reflexionar y construir como cultura de representaciones y ideales emocionales (Trommsdorff \& Cole, 2011; Tsai, 2013).Es posible entonces observar que la interacción social propia de los sujetos de grupo social mediatiza, a través de estos escenarios paradigmáticos, aquellas emociones que forman parte de lo esperable. Consecuentemente podemos 'observar' la construcción de un significado cultural de las emociones en una historia individual (Muller, Grossen, de Diesbach-Dolder \& Nicollin, 2014).

Los escenarios paradigmáticos y guiones emocionales son construidos en interacción directa con la familia y actores sociales que socializan la emoción con los niños.

1 Trad. del autor. 
Así, los elementos culturales como la literatura, música, entre otros, también aportan a la construcción de un ideal emocional. La familia, específicamente los padres, son los encargados de realizar esta socialización inicial de la emoción y gran parte de los modelos teóricos que dan cuenta de los mecanismos de socialización los ubican en el primer plano, como representantes de una educación que también es social y cultural (Bowie \& cols., 2013). Pero la escuela también funciona como un escenario paradigmático y en ella podemos observar cómo los adultos mediadores potencian una forma de expresar y regular la emoción que habitualmente es la ideal, desde el punto de vista de la cultura dominante (Tobin, Hsueh, \& Karasawa, 2009).

\section{Antecedentes sobre diferencias culturales $y$ socialización de las emociones}

Los procesos de socialización emocional se desarrollan siempre en contextos socio-históricos particulares (Cole \& Tan, 2006), donde la internalización de guiones emocionales y la representación social asociada a los mismos están mediatizadas por el contexto social y cultural en el que se construyen. Es así como el marco cultural articula la representación social de la emoción, así como el desempeño emocional de los sujetos (o saber sentir), a través de distintos mecanismos de socialización (Dunsmore \& Halberstadt, 2009; García, Crnic, Lamberty, \& Wasik, 1996; Mesquita \& Albert, 2007).

Al incluir el contexto socio-histórico de una sociedad y cultura nos referimos a las creencias compartidas, valores y costumbres que son dinámicamente transmitidas y modificadas intergeneracionalmente (Le, Ceballo, Chao, Hill, Murry, \& Pinderhughes, 2008). Estos procesos se asocian entonces a lo que es culturalmente valorado como una paternidad efectiva. Aun cuando existen aspectos del proceso de crianza que pueden ser transversal entre personas de distintas sociedades, así como una gran variabilidad individual al interior de cada sociedad, existe un considerable cuerpo de evidencia asociado al rol de la cultura en el proceso de socialización de la emoción.

En efecto, se han documentado diferencias entre amplios grupos culturales como por ejemplo, la cultura europea y americana (Estados Unidos), que ha sido consistentemente descrita como individualista y que orienta en consecuencia sus prácticas de crianza. En contraste con las culturas latinas, más interdependientes y socio-céntricas se asocian, por ejemplo, a acciones en donde el individuo siempre está en relación a otros y la familia asume un rol central en la crianza (Russell, 1991).

Junto a estas grandes diferencias, es posible observar otras más específicas que expresan lo deseable y no deseable sobre el comportamiento emocional (Soto, Levenson, \& Ebling, 2005) y por lo tanto, sobre los mecanismos de educación y socialización de la emoción. Por ejemplo, Wong, Bond, y Rodriguez (2008) exploraron la relación entre valores y expresión emocional en 25 países, donde constataron que las personas de culturas que enfatizaban las relaciones jerárquicas expresaban no verbalmente menos vergüenza, culpa o miedo, mientras que las culturas más individualistas expresaban más frecuentemente alegría. En la expresión verbal de la emoción también se han documentado diferencias culturales, por ejemplo, Hostetter, Alibali, y Niedenthal (2012) señalan que los asiáticos del este expresan menos emociones que los europeos.

Los estudios que han comparado interculturalmente la expresividad emocional parental, han evidenciado de manera consistente profundas diferencias. Por ejemplo, las madres afroamericanas y mexicoamericanas presentarían menores despliegues de atención física que las madres europeas (Ispa \& cols., 2004).La discusión parental de las emociones ha sido igualmente sometida a contraste entre distintas sociedades (Fivush \& Wang, 2005), evidenciando diferencias culturales en la forma en que los padres discuten las emociones con sus hijos. Por ejemplo, la investigación de Wang (2013) ha evidenciado que las conversaciones entre madre-hijo americanas, se caracterizan por un estilo de 'explicación de la emoción', mientras que las conversaciones de madre-hijo chinos se caracterizan por presentar un estilo de 'crítica emocional'. Entre estos mismos grupos se ha observado que, en la discusión de las emociones, las madres chinas usan más palabas asociadas a las emociones negativas que las madres americanas.

Las reacciones parentales a las emociones de los niños también constituyen mecanismos de socialización de un ideal emocional. En este campo Cheah y Sheperd (2011), compararon reacciones de madres canadiense-europeas y madres aborígenes de Canadá ante la agresión de sus hijos, pudiendo evidenciar que ambos grupos de madres respondían generalmente de manera negativa. Pero también pudo identificar diferencias en el grado de respuesta emocional, donde las madres aborígenes se mostraron menos ansiosas ante la agresión de los niños que las madres de origen europeo-canadienses. De la misma forma, Cole, Tamang, y Shrestha (2006) encontraron diferencias en las reacciones sobre la vergüenza y rabia de los niños, al comparar madres indígenas de Nepal, Tamangy Brahman, donde las primeras tendían más a reprimir la expresión emocional de los niños, mientras que las madres Brahman respondían al niño con abrazos o razonando con ellos.

Aun cuando es posible evidenciar diferencias en las distintas dimensiones del modelo propuesto por Eisenberg, Cumberland, y Spinrad (1998), los estudios llevados a cabo para explorar socialización emocional en Latinoamérica y particularmente en Chile en contextos indígenas, son aún incipientes (Henao \& García, 2009). Lo anterior puede estar asociado a la primacía de lo racional y objetivista de la investigación científica, quedando en un segundo plano u omitido la emoción como construcción social y su dimensión espiritual. Este proceso se ha visto reflejado en educación, donde, a pesar del enorme impacto en todas las dimensiones del quehacer académico, la vida emocional del estudiante ha sido históricamente mantenida al margen y minimizada (Casassus, 2006). 
Pero la escasa exploración de las variaciones culturales en la emoción en Latinoamérica y particularmente en Chile, puede deberse, además, a que damos por hecho que la forma correcta de sentir es la que define el marco social y cultural eurocéntrico hegemónico en el contexto escolar y social. Por lo tanto, no percibimos posturas críticas al modelo de ideal emocional construido en el marco social y cultural eurocéntrico occidental que se transmite de forma constante y está generalizada en la sociedad nacional. Sin embargo, observamos que el marco social y cultural mapuche que define la emoción de niños mapuches, queda invisibilizado en el desarrollo de competencias emocionales en la educación escolar.

\section{Población y estructura de la socialización emocional en la familia mapuche}

La estructura de socialización emocional mapuche está asociada a la educación familiar, sustentada en saberes y conocimientos educativos propios. Los mapuches, históricamente han habitado la zona Macro Centro-Sur de Chile, considerado como 'territorio mapuche ancestral' (Bengoa, 2008), en permanente disputa con el Estado-Nación hasta la actualidad. En dicho territorio, el Censo Nacional de Población de abril de 2002 señala que la población en Chile es de 15.116.435 habitantes, de los cuales 692.192 personas $(4,6 \%)$ pertenecen a uno de los ocho pueblos indígenas del país, de los cuales el $62,4 \%$ vive en zonas urbanas y el $37,6 \%$ en zonas rurales. El pueblo mapuche representa un $87,3 \%$ del total de la población indígena. En tanto los aymara representan el $7 \%$, los atacameños el $3 \%$. El resto de las etnias (colla, rapanui, quechua, yámana y alacalufe), en conjunto representan un 2,7\%. La región de la Araucanía representa la mayor concentración de población mapuche (203.221 habitantes), representando el 23,4 \% de la población total de esta región (INE, 2003). Estadísticas más recientes constatan que la población indígena actual es de 1.565.915 habitantes, representando el 9,1\% del total país (17.207.857); de los cuales 106.729 tienen su residencia en la región del Bio-Bio, 30.952 en la Araucanía y 209.214 en Los Lagos (Ministerio de Desarrollo Social, 2013).

La población juvenil del pueblo mapuche tiene derecho para acceder a todos los niveles del sistema educativo nacional. En el marco de la actual legislación (Ley Indígena $\left.N^{\circ} 19.253,1993\right)$, ellos tienen derecho a una educación intercultural bilingüe que les permite el aprendizaje y revitalización de su lengua vernácula mapunzugun, desde el año 1996 también se han venido incorporando educadores tradicionales que facilitan a la escuela la incorporación de saberes y conocimientos mapuches en la asignatura de lengua indígena. Los educadores tradicionales son considerados sabios y son elegidos por los miembros de la familia y de la comunidad para colaborar en la formación de los niños en la educación escolar.

Desde este contexto, las perspectivas disciplinarias que exploran y tipifican los conocimientos y saberes cul- turales mapuches se ha venido ampliando considerable y sistemáticamente, durante los últimos 15 años, entre ellas la educación intercultural, la sociología, la antropología educacional y la psicología social, entre otros (Loncon \& Martínez, 2000; Saiz, Rapimán, \& Mladinic, 2008; Quintriqueo, 2010; Quintriqueo \& Torres, 2013; Ibáñez-Salgado, 2015). Son estudios que han permitido una visión más amplia de la educación mapuche, la educación intercultural y la incorporación del conocimiento mapuche a la educación escolar. Sin embargo, hasta la fecha son pocos los estudios que han explorado las pautas de crianza implicadas en los procesos de socialización infantil en la familia mapuche (Obach \& Sadler, 2006; Cofré, 2008; Williamson, 2012). Asimismo, se observa prácticamente la inexistencia de estudios que den cuenta de la construcción y gestión del conocimiento emocional, en el marco de la sociedad y cultura mapuche.

A pesar de la inexistencia de estudios que den cuenta de la construcción y gestión del conocimiento emocional mapuche, sostenemos la hipótesis de la existencia de categorías de conocimientos emocionales propias, presentes entre los estudiantes de origen mapuche en el medio escolar. Puesto que, los autores Quilaqueo y Quintriqueo (2010) señalan que "Los saberes educativos mapuches vitales, utilizados por las familias en la formación de sus hijos, siguen vigentes entre las familias de comunidades de La Araucanía. Dichos saberes se sustentan en métodos de formación de personas y principios propios que los regulan" (p. 337). Según estos autores, la acción educativa que integra las distintas categorías de saber emocional se denomina kimeltuwün. El kimeltuwün refiere al proceso educativo mapuche que aborda aspectos que revelan quiénes aprenden, cómo y qué se enseña considerando la edad del aprendiz. Es así como dicha acción educativa está contextualiza a los contenidos de aprendizaje del medio natural, social y cultural (especialmente la espiritualidad) en que se sustenta el desarrollo de la familia y la comunidad (Quilaqueo \& Quintriqueo, 2010). Entre los principios educativos señalados por Quintriqueo, Quilaqueo, Gutiérrez y Peña-Cortés (2015, p. 121), se destacan los siguientes: 1) "kümeyawalta che", asociado a la actitud de respeto que idealmente se debe dar entre las personas de la familia y la comunidad; 2) "yamüwalta che", asociado al reconocimiento y estima entre personas de la comunidad mapuche en general; 3) "kümerakizuamtanieael", refiere a la necesidad de desarrollar un pensamiento requerido en la familia y la comunidad; 4) "küme che geal", que refiere a un modelo de persona solidaria; 5) "kim che geal", asociado a la formación de la persona sustentada en el conocimiento; 6) "kümeinayaltañizugu", refiere a una persona que debe actuar correctamente, ser firme en una forma de pensar; 7) "ajkütualtazugu", significa formar una persona que se capaz de saber escuchar; y 8) "kümekegübamtayenieael", que significa ser una persona portadora del buen consejo.

Asimismo, el kimeltuwün incluye elementos como la responsabilidad familiar en la enseñanza, la exclusividad de los padres y abuelos en la entrega de conocimientos cotidianos para la formación de las personas. Los padres y los familiares más cercanos que intervienen en la formación 
durante la niñez utilizan diversas estrategias de acción que constituyen elementos diferenciadores en la formación mapuche como lo es el gübamtun (o arte de aconsejar) (Caro \& Terencán, 2006). En este proceso se utilizan distintas prácticas de acuerdo a las situaciones específicas, o momentos particulares de la vida cotidiana, con códigos diferentes y estrategias distintas para el aprendizaje de los hijos. Entre las que se destacan son: el epew (relatos fundacionales), el feyentun (contenidos referidos a la obediencia), el nüxam (referido a un método educativo) y el gübam (referido a un método de enseñanza) que abordan contenidos valóricos, míticos e históricos de la comunidad (Quilaqueo \& Quintriqueo, 2010).

Junto a la familia, junto a los miembros de la comunidad, es un participante activo en la socialización emocional, en particular los kimches, hombres y mujeres, quienes son considerados sabios y sabias portadores del conocimiento social y cultural, depositarios de saberes específicos sobre la formación de personas. Los kimches, basándose en el kimeltuwün, trasmiten a niños y niñas de origen mapuche sobre saberes culturales ancestrales, contenidos actitudinales relacionados con la memoria social mapuche (Quilaqueo \& Quintriqueo, 2010; Quilaqueo, 2012). Desde lo señalado en el marco de la socialización del niño mapuche, es posible distinguir procesos educativos que se relacionan con la discusión de la emoción en el marco de la formación de la persona, así como principios emocionales que se construyen socialmente en este proceso.

En conclusión, considerando la propuesta de Goetz, Spencer-Rodgers, y Peng (2008), proponemos que los procesos dialógicos en el marco de epistemologías culturales, como los señalados en el kimeltuwün en la familia mapuche, influencian la experiencia y regulación emocional de quienes forman parte de ella. De allí, surgen herramientas de socialización emocional que orientan la forma de actuar, que se someten a contraste en los contextos de diversidad social y cultural. Es el caso de la escuela y el sistema educativo en general. Lo anterior tiene implicancias, también, para el desempeño del estudiante en contextos educativos escolares que igualmente buscan aportar a la formación de personas, pero desde una lógica occidental con lineamientos de comportamiento distintos (Kim \& Markus, 2002).

\section{Para finalizar}

Como agente socializador, la escuela no sólo educa formalmente a través del currículum escolar, educa también en función de las normas morales y éticas que pueden estar en mayor o menor medida explícitas en su quehacer y en su interacción social habitual (Perrenoud, 1996). Es decir, un adecuado proceso de educación debe hacer explícitos los ideales formativos en el campo de la emoción, en particular en la educación en contextos de diversidad social y cultural, principalmente en contextos indígenas. Lo anterior implica reflexionar sobre la educación emocional que explícita o implícitamente estamos entregando a nuestros estudiantes.
La educación en contextos de diversidad social y cultural, en el caso mapuche, no pasa sólo por incorporar sus conocimientos culturales y saberes propios en el currículum escolar, sino que además, es necesario comprender los procesos emocionales que subyacen a las dinámicas culturales expresadas conductualmente en el contexto educativo. Esto implica el reconocimiento de la importancia de las normas sociales y emocionales que pueden diferir entre los sujetos pertenecientes a distintas culturas que se hacen evidentes en las relaciones interculturales. Lo anterior es particularmente relevante al considerar que el desarrollo de competencias emocionales, como el reconocimiento, expresión y regulación de emociones son parte de los programas pedagógicos en educación preescolar (MINEDUC, 2008). Esto permitirá tener una visión actual de los componentes emocionales que subyacen a un comportamiento escolar, pero se pretende comprender además, cómo los patrones de representación emocional presentes desde un discurso histórico deben ser modificados en base a las demandas socio-educativas de una educación occidental dominante y excluyente.

La contribución de la psicología social a la educación es, en este punto, fundamental. La psicología debe contribuir mediante la investigación histórica-documental y empírica de los saberes emocionales propios de pueblos indígenas, en miras a una revisión de los modelos europeos y occidentales sobre lo que es deseable para un niño en su desarrollo emocional. En este marco, esta construcción teórica debe dar cuenta de una pluralidad epistemológica que incluya tanto las visiones occidentales como indígenas por igual. Lo anterior permitirá develar los conocimientos propios de estas culturas y aportar de esta forma a su revitalización.

La psicología también puede contribuir a este objetivo, a través de la exploración de las creencias y representaciones que el cuerpo académico de las escuelas tiene en relación a las minorías, lo mismo sobre las creencias que mantienen sobre las minorías de los formadores de profesores en las universidades. Lo anterior, es necesario para la develar aquellas creencias y estereotipos que mantienen la primacía de un ideal emocional occidental y europeo, así como el racismo y tendencia a la 'normalización' de niños de culturas minoritarias, como ha sido el caso de los mapuches en Chile.

En esa perspectiva, el conjunto de contenidos y principios educativos explicitados por Quintriqueo y cols. (2015) para la formación de personas, constituye los saberes y conocimientos propios de la educación familiar, que tienen implicancias directas en la construcción de competencias emocionales de niños y niñas mapuches. Estas competencias emocionales al estar sustentadas en la dimensión natural (relación hombre naturaleza), social, cultural y espiritual, se construyen como representaciones sociales que se viven desde la intersubjetividad, para dar sentido al actuar de los niños y niñas en el marco social y cultural mapuche. En efecto, desde un enfoque educativo intercultural, el desafío es considerar en la educación escolar los procesos de socialización emocional sustentados en la epistemolo- 
gía indígena, en este caso mapuche, para responder a los contextos socio-históricos particulares en que se inscribe la escuela postcolonial. Esto implica abogar por una pluralidad epistemológica para comprender otras formas de educación emocional en el contexto escolar, que articule el diálogo de saberes y las relaciones interculturales entre profesores y estudiantes y viceversa, sean mapuches y no mapuches.

Finalmente, la necesidad de una educación emocional escolar con pertinencia cultural, implica que la psicología educacional y la escuela no solo deben analizar sobre cuáles son los contenidos que los estudiantes deben conocer para cumplir con un ideal académico, debe también reflexionar sobre cuál es el ideal que en plano emocional está transmitiendo. Y de la misma forma, debe saber escuchar cuáles son los ideales emocionales que están representados en los niños y niñas de culturas minoritarias y dominadas que asisten a en las escuelas.

\section{Referencias}

Bengoa, J. (2008). Historia del pueblo mapuche Siglo XIX y XX. Ediciones del Sur, Colección Estudios Históricos. ( $7^{\mathrm{a}} \mathrm{Ed}$.). Santiago: Imp. Editorial Interamericana Ltda.

Bisquerra, R. \& Pérez, N. (2007).Las competencias emocionales. Educación XX1(10), 61-82.

Boiger, M. \& Mesquita, B. (2012). The construction of emotion in interactions, relationships, and cultures. Emotion Review, 4(3), 221-229.

Bowie, B., Carrère, S., Cooke, C., Valdivia, G., McAllister, B., \& Doohan, E. (2013). The Role of Culture in Parents' Socialization of Children's Emotional Development. Western Journal of Nursing Research, 35(4), 514-533.

Caro, A. \& Terencán, J. (2006).El Ngülam en el discurso intrafamiliar mapuche. Revista de Ciencias Sociales de la Universidad Iberoamericana, 1(1), 1-9.

Casassus, J. (2006). La educación del ser emocional. Santiago de Chile: Editorial Cuarto Propio.

Cheah, C. \& Sheperd, K. (2011). A Cross-Cultural Examination of Aboriginal and European Canadian Mothers' Beliefs regarding Proactive and Reactive Aggression. Infant and Child Development, 20(3), 330-346.

Chentsova-Dutton, Y.E.\& Wong, Y. (2002). Why and how we should study ethnicidentity, acculturation, and cultural orientation. Em G. Hall \& S. Okazaki (Orgs.), Asian American psychology: Scientific innovations for the 21st century (pp. 41-65). Washington, DC: American PsychologicalAssociation.

Cofré, M. (2008). Sistematización del Taller Pautas de Crianza Mapuche. Recuperado: 22 mar. 2014. Disponível: http://www.
unicef.cl/unicef/public/archivos_documento/276/WD_Pautas_de_ crianza_mapuche.pdf

Cole, P. \& Tan, P. (2006). Capturing the culture in the cultural socialization of emotion.International Society for the Study of Behavioral Development Newsletter, 1(49), 5-7.

Cole, P., Tamang, B., \& Shrestha, S. (2006). Cultural Variations in the Socialization of Young Children's Anger and Shame. Child Development, 77(5), 1237-1251.

DeAnquín, A. \& Bazán, M. D. (2015).Experiencias Pedagógicas Interculturales: Sobre los Desafíos a la Educación en la Frontera Noroeste de Argentina. Journal of Latinos and Education, 14(2), 106-115.

De Leersnyder, J., Mesquita, B., \& Kim, H. (2013).Emotional Acculturation. Em Dirk Hermans, BatjaMesquita, \& Bernard Rime (Orgs.), Changing Emotions (pp. 127-133). Hove, East-Sussex: Psychology Press.

De Sousa, R. (1990). The Rationality of Emotion. Cambridge: MIT Press.

Denham, S. A., Bassett, H. H., \& Zinsser, K. (2012).Early Childhood Teachers as Socializers of Young Children's Emotional Competence. Early Childhood Education Journal, 40(3), 137-143.

Dunsmore, J. C. \& Halberstadt, A. G. (2009).The dynamic cultural context of emotion socialization. Em J. A. Mancini, K. A. Roberto, J. A. E. Mancini, \& K. A. E. Roberto (Orgs.), Pathways of human development: Explorations of change (pp.171-190). Lanham, MD: Lexington Books.

Eisenberg, N., Cumberland, A., \& Spinrad, T. (1998). Parental socialization of emotion. Psychological Inquiry, 9, 241-273.

Fivush, R. \& Wang, Q. (2005). Emotion Talk in Mother-Child Conversations of the Shared Past: The Effects of Culture, Gender, and Event Valence. Journal of Cognition and Development, 6(4), 489-506.

Foley, D. (2004). El indígena silencioso como una producción cultural. Cuadernos de Antropología Social, 19,11-28.

Friedlmeier, W., Corapci, F., \& Cole, P. M. (2011). Emotion Socialization in Cross-Cultural Perspective.Social \&Personality Psychology Compass, 5(7), 410-427.

Gallimore, R. \& Hu-Pei Au, K. (2002). La paradoja de la competenciaincompetencia en la educación de los niños de minorías culturales. Em M. Cole., Y. Engeström, \& O. Vásquez (Orgs.), Mente, cultura y actividad (pp. 196-206). España: Oxford University Press, Clarendon Press.

García, C., Crnic, K., Lamberty, G., \& Wasik, B. (1996). An integrative model for the study of developmental competencies in minority children. Child Development, 67, 1891-1914. 
Goetz, J., Spencer-Rodgers, J., \& Peng, K. (2008). Dialectical Emotions: How Cultural Epistemologies Influence the Experience and Regulation of Emotional Complexity. Em R. Sorrentino \& S. Yamaguchi (Orgs.), Handbook of Motivation and Cognition Across Cultures (pp. 517-539). San Diego: Academic Press.

Halberstadt, A. G. \& Lozada, F. T. (2011). Emotion Development in Infancy through the Lens of Culture. Emotion Review, 3(2), 158-168.

Henao, G. C. \& García, M. C. (2009). Interacción familiar y desarrollo emocional en niños y niñas. Revista Latinoamericana de Ciencias Sociales, Niñez y Juventud, 7, 785-802.

Hostetter, A., Alibali, M., \& Niedenthal, P. (2012). Embodied social thought: Linking social concepts, emotion, and gesture. Em S. Fiske \& C. Macrae (Orgs.), The SAGE handbook of social cognition.(pp. 211-229). London: SAGE Publications Ltd.

Ibanez, N; Diaz, T; Druker, S., \& Rodriguez, M. (2012) La comprensión de la diversidad en interculturalidad y educación. Convergencia [online], 19(59), 215-240.

Ibáñez-Salgado, N. (2015).La diversidad en la construcción de mundo de niños y niñas de dos culturas. Revista Latinoamericana de Ciencias Sociales, Niñez y Juventud, 13 (1), 357-368.

Instituto Nacional de Estadísticas (INE), (2003). Censo 2002 Resultados, Volumen I, Población, País, Regiones. Santiago de Chile.

Ispa, J., M. Fine, M. A., Halgunseth, L. C, Harper, S., Robinson, J., Boyce, L., Brooks-Gunn, J., \& Brady-Smith, C. (2004). Maternal Intrusiveness, maternal warmth, and mother-toddler relationship outcomes: Variations a cross low income ethnic and acculturation groups. Child Development, 75(6), 1613-1631.

Kim, H. S. \& Markus, H. R. (2002).Freedom of speech and freedom of silence. Em R. A. Shweder, M. Minow, \& H. R. Markus. (Orgs.), Engaging cultural differences: the multicultural challenge in liberal democracies (pp. 432-452). New York: Russell Sage Fundation.

Le, H.N., Ceballo, R., Chao, R. Hill, N.E., Murry, V. M., \& Pinderhughes, E. E. (2008).Excavating Culture: Disentangling Ethnic Differences from Contextual Influences in Parenting. Applied Developmental Science, 12 (4), 163-175.

Lewis, M. (1989). Cultural differences in children's knowledge of emotional scripts. Em C. Saarni \& P. Harris (Orgs.), Children's Understanding of Emotion (350-373). Cambridge: Cambridge University Pres.

Lewis, M. (2008).The emergence of human emotions. Em M. Lewis, J. Haviland-Jones, \& L. Feldman Barrett (Eds.), Handbook of emotions, 3rd ed. (pp. 304-319).New York: Guilford Press.

Ley $n^{\circ} 19.253$ D. of. $5^{\circ} 10^{\circ} 1993(1993)$. Ley Indígena. Temuco: Corporación Nacional de Desarrollo Indígena - CONADI.
Loncon, E. \& Martínez, C. (2000). Pichikeche. Guía intercultural para la educación preescolar. Fundación Integra - I.M. San Pedro de la Paz - SIEDES, Temuco. Chile.

Mesquita, B. \& Albert, D. (2007).The cultural regulation of emotions. Em J. J. Gross (Org.), The handbook of emotion regulation (486503). New York: Guilford Press.

MINEDUC. (2008). Programa Pedagógico. Primer Nivel de Transición. Chile: Gobierno de Chile.

Ministerio de Desarrollo Social (2013), Encuesta de Caracterización Socioeconómica Nacional [CASEN]. Chile: Gobierno de Chile.

Muller, M., Grossen, M., de Diesbach-Dolder, S., \& Nicollin, L. (2014). Transforming personal experience and emotions through secondarisation in education for cultural diversity: An interplay between unicity and genericity. Learning, Culture and Social Interaction.

Obach, A. \& Sadler, M. (2006).Estudio Significaciones, Actitudes y Prácticas de Familias Mapuches en elación a la Crianza y Cuidado Infantil de los Niños y Niñas desde la Gestación hasta los Cinco Años. Chile: Gobierno de Chile.

Perrenoud, P. (1996). La construcción del éxito y del fracaso escolar. Madrid: MORATA.

Quilaqueo, D. (2012). Saberes educativos mapuche: racionalidad apoyada en la memoria social de los kimches. Atenea, 505, 70-102.

Quilaqueo, D. \& Merino, M. (2003). Estereotipos y prejuicio étnico hacia los mapuches en textos complementarios a la asignatura de Historia. Revista Campo Abierto, 23, 119-135.

Quilaqueo, D., Merino, M., \& Saiz, J. (2007). "Representación social mapuche e imaginario social no mapuche de la discriminación percibida". Revista Atenea, 496, 81-103.

Quilaqueo, D. \& Quintriqueo, S. (2010). Saberes educativos mapuches: un análisis desde la perspectiva de los kimches, Polis [En línea], 26. Recuperado: 24 abr. 2014. Disponível: http://polis. revues.org/808.

Quintriqueo, S. (2010). Implicancias de un modelo curricular monocultural en contexto mapuche. Santiago, Chile: Gráfica LOM.

Quintriqueo, S., Quilaqueo, D., Le pe-Carrión, P., Riquelme, E., Gutiérrez, M., \& Peña-Cortés, F. (2014).Formación del profesorado en educación intercultural en América Latina. El caso de Chile. Revista Electrónica Interuniversitaria de Formación del Profesorado, 17(2), 201-217.

Quintriqueo, S., Quilaqueo, D., Gutiérrez, M. \& Peña-Cortés, F. (2015). Enseñanza de Historia, Geografía y Ciencias Sociales: hacia una Perspectiva Intercultural. Temuco: Editorial Universidad Católica de Temuco. 
Quintriqueo, S. \& Torres, H. (2013). Construcción de Conocimiento Mapuche y su relación con el Conocimiento Escolar. Estudios pedagógicos, 39, 199-216.

Riquelme, E. \& Montero, I. (2013). Improving Emotional Competence Through Mediated Reading: Short Term Effects of a Children's Literature Program. Mind, Culture, and Activity, 20(3), 226-239.

Riquelme, E. \& Munita, F. (2013). Lectura Mediada y Escenarios Paradigmáticos Ficticios. Actas Del Seminario Internacional ¿Qué leer? ¿Cómo leer?, Perspectivas sobre la Lectura en la Infancia (pp. 349-364). Plan de Fomento Lector del Ministerio de Educación de Chile.

Riquelme, E. \& Munita, F. (2016). The Mediated reading of children's literature as "paradigmatic scenario" in the development of emotional competence: explore the fictional line to change the real script. Psicología, Teoría \& Pesquisa. In press

Riquelme, E., Munita, F., Jara, E., \& Montero, I. (2013). Reconocimiento facial de emociones y desarrollo de la empatía mediante la lectura mediada de literatura infantil. Cultura y Educación, 25(3), 375-388.

Russell, J. (1991).Culture and the categorization of Emotions. Psychological Bulletin, 10(3), 246-450.

Saarni, C. (1999). The development of emotional competence. New York: The Gilford Press.

Saarni, C. (2008). The interface of emotional development with social context. Em M. Lewis, J. Haviland-Jones \& L. Feldman Barrett (Orgs.),Handbook of Emotions (3a ed., pp. 332-347). New York: Guilford Press.

Saiz, J., Rapimán, M., \& Mladinic, A. (2008).Estereotipos Sobre los Mapuches: Su Reciente Evolución. Psykhe, 17, (2), 27-40

Soto, J., Levenson, R., \& Ebling, R. (2005). Cultures of Moderation and Expression: Emotional Experience, Behavior, and Physiology in Chinese Americans and Mexican Americans. Emotion. 5(2), 154-165.

Tobin, J., Hsueh, Y., \& Karasawa, M. (2009).Preschool in Three Cultures Revisited: China, Japan, and the United States. Chicago, IL: University of Chicago Press.
Tremblay, M., Gokiert, R., Georgis, R., Edwards, K., \& Skrypnek, B. (2013). Aboriginal Perspectives on Social-Emotional Competence in Early Childhood. The International Indigenous Policy Journal, 4(4). Recuperado: 10 Mar. 2014. Disponível: http://ir.lib.uwo.ca/iipj/ vol4/iss $4 / 2$

Trommsdorff, G., \& Cole, P. M. (2011). Emotion, self-regulation, and social behavior in cultural contexts, in Chen and K. H. Rubin (Eds.), Socioemotional Development in Cultural Context(131-163). New York, NY: Guilford Press.

Tsai, J. L. (2013). The cultural shaping of emotion (and other feelings). Em R. Biswas-Diener \& E. Diener (Orgs.), Noba textbook series: Psychology. Champaign, IL: DEF Publishers.

Wang, Q. (2013). Chinese socialization and emotion talk between mothers and children in native and immigrant Chinese families. Asian American Journal of Psychology, 4(3), 185-192.

Widen, S. \& Russell, J. (2010). Children's scripts for social emotions: Causes and consequences are more central than are facial expressions. British Journal of Developmental Psychology, 28, 565-581.

Widen, S. \& Russell, J. (2011). In building a script for an emotion, Do Preschoolers Add its Cause Before Its Behavior Consequence? Social Development, 20(3), 471-485.

Williamson, G. (2012). Educación en la Araucanía. El mirar de los niños y niñas mapuche sobre sí mismos. Revista Chilena de Pediatría, 83(6), 529-532

Wong, S., Bond, M., \& Rodriguez Mosquera, P. (2008). The influence of cultural value orientations on self-reported emotional expression across cultures. Journal of Cross-Cultural Psychology, 39(2), 224229.

Zembylas, M. (2011).Investigating the emotional geographies of exclusion at a multicultural school.Emotion, Space and Society, 4(3), 151-159.

Zubieta, E., Fernández, I., Vergara, A.I., Martínez, M. D., \& Candia, L. (1998). Cultura y emoción en América. Boletín de Psicología, 61, 65-89. 


\section{Sobre os autores}

Enrique Riquelme Mella (eriquelme@uct.cl)

Es profesor asistente de la Facultad de Educación de Universidad Católica de Temuco, Chile. Sus estudios se encuentran asociados a las variaciones culturales de la regulación emocional. Es Doctor por la Universidad Autónoma de Madrid. Investigador del Centro de Investigación en Educación en Contextos Indígenas e Interculturales (CIECII).

Daniel Quilaqueo Rapimán (dquilaq@uct.cl)

Dr. en Sociología de l'Université de la Sorbonne, París, Francia. Profesor Titular de la Facultad de Educación de la Universidad Católica de Temuco. Director del Centro de Investigación en Educación en Contextos Indígenas e Interculturales (CIECII), Investigador Titular del Núcleo de Estudios Interétnicos e Interculturales (NEII) de la UC Temuco; es Investigador Asociado del Centre Interuniversitaire d'Études et de Recherches Autochtones (CIÉRA) de l'Université Laval, Québec, Canadá.

\section{Segundo Quintriqueo Millán (squitri@uct.cl)}

Profesor Asociado de la Facultad de Educación de la Universidad Católica de Temuco, Investigador del Centro de Investigación en Educación en Contexto Indígena e Intercultural (CIECII), Investigador del Núcleo de Estudios Interétnicos e Interculturales (NEII), UCT, Chile e Investigador Asociado del Centre Interuniversitaire d'Études et de Recherches Autochtones (CIÉRA) de I'Université Laval, Québec, Canadá.

Elisa Loncón Antileo (elisa.loncon@usach.cl)

Académica de la Universidad de Santiago de Chile (USACH, es profesora de inglés por la Universidad de La Frontera, Temuco (Chile), con cursos de postítulo en el Instituto de Estudios Sociales de la Haya (Holanda) y en la Universidad de Regina (Canadá). Posee un Magíster en lingüística de la Universidad Autónoma Metropolitana, Iztapalapa UAM-I (México). Además es Estudiante de Doctorado en Lingüística, Universidad de Leiden (Holanda).

Este artículo se enmarca en los proyectos FONDECYT de iniciación 1140311 "Socialización emocional en la educación familiar mapuche"; FONDECYT Regular N 1140562, "Construcción social del conocimiento educativo mapuche: doble racionalidad y desafíos para una escolarización intercultural” y FONDECYT Regular N¹140490“Conocimientos geográficos y territoriales mapuches: una base para la formulación de contenidos educativos interculturales pertinentes y contextualizados". 